\title{
Worker Saturation in Facing Changes in the Work Environment: The Physiological Impact of Online Jobs
}

\author{
Napasorn Thongprasom ${ }^{1}$, Whirathep Pow ${ }^{2}$, Youyen Pukklaw ${ }^{2}$ \\ ${ }^{1}$ Social Science Faculty, Chulalongkorn University, Thailand \\ ${ }^{2}$ Faculty of Social Sciences, Naresuan University, Thailand \\ Received: November 19, 2021 \\ Received in Revised: December 23, \\ Accepted: December 31, 2021 \\ 2021
}

\begin{abstract}
This article discuss about worker saturation in facing changes in the work environment in the physiological impact of online jobs. During the Covid-19 epidemic, social segregation was implemented, and employees worked from home (WFH) via online platform. Some workers get saturation in facing the situation. A process that makes individuals feel ill, uneasy, or anxious as a result of their employment, workplace, or work circumstance. The capacity to adapt to and appreciate current circumstances transforms stress from distress to eustress. Effective stress management tactics include regular exercise, setting aside time for relaxation and self-care, balancing work and pleasure, and practicing time management and meditation.
\end{abstract}

Keywords: Physiological, Worker Saturation, Work Environment

\section{Introduction}

Employees in the operational department confront several job hazards, such as inhospitable road conditions or scenarios, and they must be able to adapt to their surroundings and optimize their time available to perform their task more successfully and efficiently. Employees must be able to complete work in a single location on time to avoid work being postponed that day. If work is delayed that day, they must do it the next day, increasing their workload the following day. Employee burnout is influenced by a variety of factors, including task demands, social support, work environment, interpersonal friction amongst coworkers, and job satisfaction.

The organization is constantly striving to deliver the highest-quality goods and services, employees must be able to fulfill their assigned responsibilities on time. However, businesses frequently assign excessive work to their employees without regard for the employee's condition of readiness to pursue aims. This might result in staff burnout as a result of the excessive work expectations placed on personnel. Employees are required to forego rest time in order to complete their tasks, they are required to work overtime and return home late at night (Rubery et al., 2005). Many employees experience psychological and physical fatigue, which results in emotional exhaustion as a result of working under pressure every day (Gaines \& Jermier, 1983; Peterson et al., 2008).

Social support is critical in many facets of an individual's life, given that humans are social beings who are constantly in contact with one another (DiMatteo, 2004). Other people's support is critical for an employee's smooth work process, and so affects a person's performance and psyche. Social support may have an effect on an employee's performance since it increases employee self-motivation. The help of colleagues, it will have an effect on one's capacity to adjust to everyday life's changes and obstacles. On the other side, without coworker support, it can result in emotions of hopelessness, worthlessness, and isolation, to the point that employees who lack coworker support tend to be distant and indifferent. Individuals with a high level of 
social support will have a more favorable opinion of themselves and their job than those with a low level of social support.

The work environment has a critical role in boosting employee morale, as it helps employees avoid boredom and mental tension that are frequently encountered by individuals (McCoy \& Evans, 2005). A pleasant, safe, and conducive work environment will be produced if all parties desire order at work in order for an employee to avoid boredom, but this lack of attention to the work environment has negative consequences, such as employees being hesitant to work due to a lack of space. Work that is not conducive or pleasant interferes significantly with employee focus, ultimately resulting in employee burnout.

Interpersonal problems between coworkers are a role in the likelihood of burnout (Maslach \& Leiter, 2016). Humans are social beings that are unable to live apart from their communities regardless of their location. However, modern working circumstances in a variety of corporate sectors are more focused on financial gain in the short term, frequently overlooking the human aspect. Competitive, individualistic, and achievement-oriented work environments can induce emotions of discomfort since social interactions and detachment from the social environment really create a sense of uneasiness for someone, which can quickly escalate into conflict.

Interpersonal connections commonly arise, displaying uncooperative attitudes and misconceptions as a result of the effect of burnout. Problems that should be solvable intellectually and rationally are occasionally handled through emotion; conflict resolution frequently consumes a great deal of energy and can quickly lead to saturation.

The second element affecting job saturation in employees is job satisfaction. Job satisfaction may be derived from a variety of factors, including the work environment's comfort, the awards received, the promotions received, the supervision received, and the interaction between coworkers. However, many employees, particularly those who operate in the field, are dissatisfied with the services offered by the corporation, resulting in employment saturation. Employees at PT Infomedia Nusantara report low job satisfaction for a variety of reasons, including monotonous work that causes employees to feel bored, erratic work hours that result in insufficient employee rest time, lack of promotions, inadequate supervision from superiors that causes employees to be less responsible in their work, and coworkers who are not invited to collaborate on tasks. Employees who are content with their job feel reduced boredom; on the other side, employees who are dissatisfied with their work suffer excessive boredom, which results in decreased employee enthusiasm and performance.

During the Covid-19 epidemic, social segregation was implemented, and employees worked from home (WFH). All offices and establishments are closed. Additionally, factories were shuttered. This is not a huge issue for people who can work from home. However, compelling workers in the service and manufacturing industries to report to work may create complications. The lack of confidence regarding the end date of the COVID-19 epidemic generates concern for companies and employees. Numerous businesses make layoffs as a result of activity slowdown. Meanwhile, those who continue to do business see their productivity decline. These are only a few of the factors that contributed to workplace stress during the Covid-19 epidemic. A process that makes individuals feel ill, uneasy, or anxious as a result of their employment, workplace, or work circumstance. Stress is a term that refers to a person's bodily and psychological reaction to a change in his surroundings that he perceives as unsettling and threatening (Janis, 2016). Conditions of stress will have an effect. The purpose of this article to know worker saturation in facing changes in the work environment in the physiological impact of online jobs. 


\section{Literature review}

\section{The Concept of Worker Saturation}

Exhaustion is a form of burnout that is characterized by prolonged physical, mental, and emotional exhaustion (Kakiashvili et al., 2013). When staff are exhausted, they are unable to resolve problems (exhaustion). Even with appropriate rest, an individual will suffer exhaustion and a deficiency of energy to do daily chores. A worker who is emotionally weary may experience a substantial loss of energy as he prepares for tomorrow and the people in his work environment. Depersonalization is a conscious attempt to establish a barrier between oneself and service consumers by deliberately ignoring the features that distinguish and intrigue them as people. When employees are skeptical, they are likely to be aloof, maintain a safe distance, and avoid interaction in their work environment. Withdrawal is a natural response to exhaustion. Burnout research has consistently established a substantial correlation between tiredness (exhaustion) and cynism (depersonalization) in a range of organizational and professional settings.

A personal accomplishment is an instance in which a person evaluates himself. Workers who have had significant personal accomplishment will also have a high level of achievement drive. On the other side, when an individual's personal accomplishments are small, their motivation to strive diminishes. Additionally, additional research reveals that a lack of drive to accomplish results in an individual developing a negative self-perception. When a person's own accomplishments are inadequate, he or she feels helpless and has the sense that all prescribed jobs are onerous. Employees typically develop a sense of inadequacy when they believe themselves to be unproductive. Each assignment looks to be difficult and hard to complete, diminishing confidence. Workers develop self-doubt, while others acquire suspicion of them. Burnout can result in a decline in the quality of work, manifested by withdrawal from work, increased tardiness and absenteeism, and decreased job performance and quality. As evidenced by the prevalence of physical, psychological, and behavioral issues, burnout can have an effect on individuals. (1) Physical ailments, in which stress has an effect on the body of an individual. When people are stressed, the majority of people have headaches. Heart disease is also one of the most bothersome signs of the condition for those who are stressed. Additionally, stroke and hypertension will develop; (2) Psychological illnesses include work discontent, mood swings, and sadness. Behavioral problems, including burnout, can result in job absence on the grounds that they make employees ill. Additionally, it leads in aggressiveness among vocal and nonverbal workers alike. Workers become aggressive when they encounter unfairness, irritation caused by their inability to control themselves, and a demanding work environment. According to the description above, the effect of burnout on employees is that it can result in physical, psychological, and behavioral difficulties, causing people to disengage from their jobs.

There are two significant factors that influence someone's likelihood of experiencing burnout at work. The first component is the work environment, which is classified into six categories, and the second factor is the individual. The following is a comprehensive explanation of this; (1) Workplace considerations, Overloading the workload can emerge as a result of a mismatch between workers and their jobs. Burnout can arise as a result of repetitive work environments or a lack of variation. Previous study has revealed elevated levels of stress in those who are overworked. Long or unpredictable work hours, an excessive number of responsibilities, working at a rapid pace, making an excessive number of phone calls, dealing directly with difficult people without adequate assistance, supervising an excessive number of people (e.g., large class sizes and overcrowding), or having a broad job description are all characteristics of overwork. Additionally, monotonous job or employment that lacks variation might contribute to burnout. The control in question is the scenario in the workplace that exerts an excessive 
amount of control over employees. Everyone want the capacity to make choices and judgments, to think critically and solve difficulties, and to accomplish goals. The prevalence of regulations sometimes constrains workers' ability to innovate, since they feel less accountable for the outcomes as a result of excessive control from superiors. Additionally, rewards are frequently referred to as presents or recognition for an accomplishment. Employees feel useless when their work environment is not appreciated. Appreciation is not just manifested via the awarding of incentives (money), but also through positive relationships between coworkers, coworkers, and superiors. Appreciation increases workers' positive affection, which is also a vital factor in demonstrating that someone has performed successfully; (2) Individual determinants include demographic determinants. Gender, ethnic origin, age, marital status, and educational background are all considered demographic determinants, as as personality traits such as introverted or extroverted personality types, self-concept, needs, motivation, capacity to manage emotions, and locus of control. According to the definition above, the elements that contribute to burnout may be classified into two categories. The first issue is the work environment, which includes labor overload and tedious job, control, insufficient incentives, employee disputes, a sense of injustice, and value conflicts. Individual characteristics include gender, ethnic origin, age, marital status, educational background, and personality characteristics such as introverted or extroverted personality types, self-concept, needs, motivation, capacity to manage emotions, and locus of control.

\section{The Physiological Impact of Online Jobs}

Burnout can result in a decline in the quality of work, as seen by withdrawal from work, increased tardiness and absenteeism, and decreased job performance and quality. Burnout may have an effect on individuals as evidenced by the prevalence of physical, psychological, and behavioral issues. When people are stressed, the majority of people have headaches. Heart disease is also one of the most bothersome signs of the condition for those who are stressed. Additionally, stroke and hypertension will develop; (2) Psychological disorders include job discontent, mood swings, and despair; and (3) Behavioral disorders, namely persons who suffer burnout, might result in work absence on the grounds that they have made employees unwell. Additionally, it leads in aggressiveness among vocal and non-verbal workers alike. Workers become aggressive when they encounter unfairness, irritation caused by their inability to control themselves, and a demanding work environment.

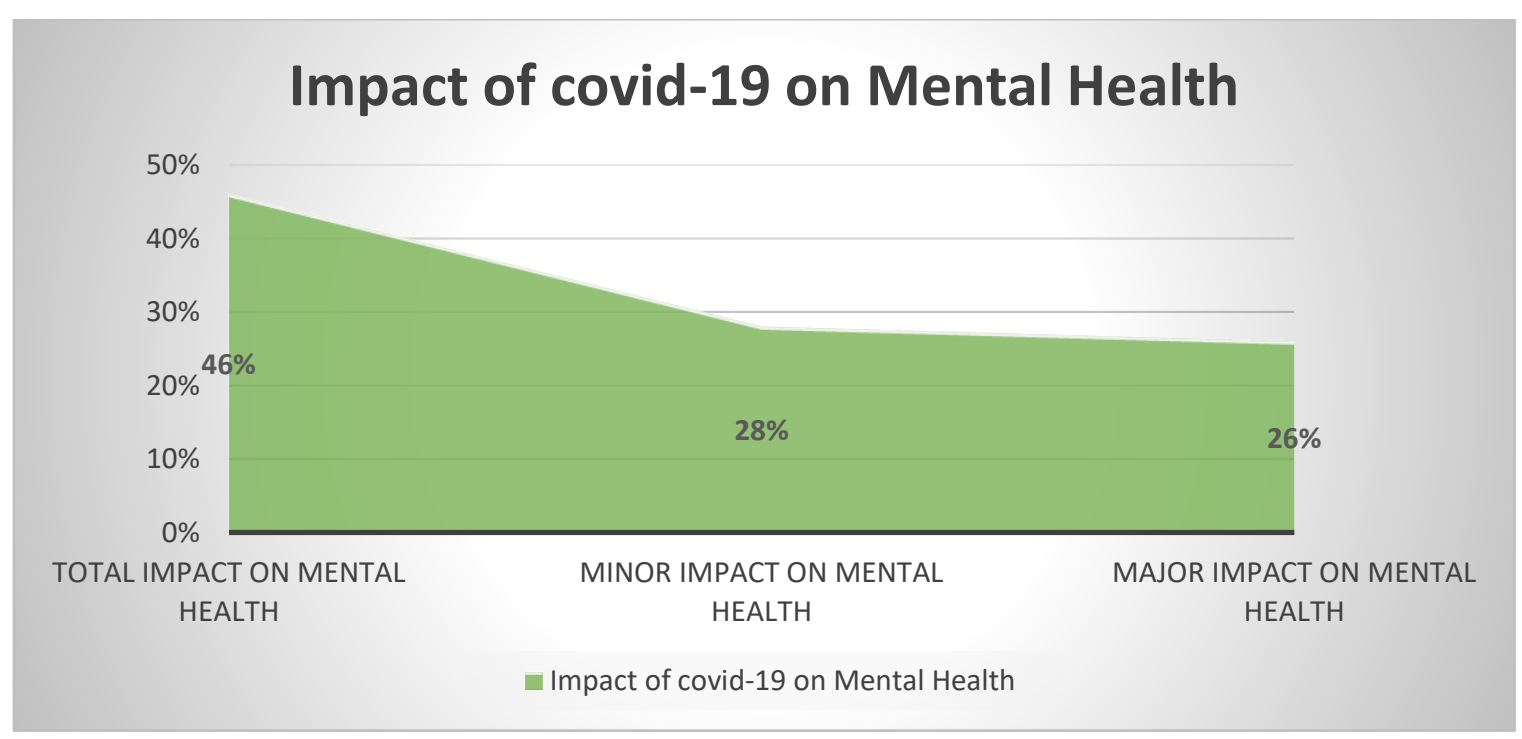

Figure 1. Impact of covid-19 on Mental Health 
This condition might make an employee fearful about the future of the job he now has. There is a sense of foreboding and helplessness as they attempt to overcome obstacles that might jeopardize the continuation of their work in the future. This insecurity in the workplace occurs not only as a result of the threat of losing a job, but also as a result of the threat of losing other important benefits, such as monthly income, missed opportunities for additional and increased income, delays in promotion opportunities, and delays in determining employee status. When we feel uneasy at work, it can have a negative effect on our psychological and physical health (anxiety, depression, stress, feelings of worthlessness, hopelessness, reduced self-confidence, psychosomatics, increased blood pressure, to heart problems). Additionally, this state causes us to be unsatisfied with our existing jobs, retreat, and demonstrate a lack of dedication to completing duties.

\section{The Scope of Stress during the Covid-19 Pandemic}

\section{Work Stress}

When the prevailing conditions are considered, occupational stress during the covid pandemic is a result of social isolation, which results in decreased communal activities. As a result, productivity is reduced. On the other hand, workers who have begun using WFO (Work From Office) are filled with anxiety, which results in tension, as they fear being exposed to the corona virus, as recent news reports indicate the formation of new clusters in offices. These diseases are caused, among other things, by personnel who lack discipline when it comes to following health procedures. Humans are social beings that thrive when they are able to interact with other people. They will feel isolated if they are forced to spend all of their time at home. If such a circumstance persists, it will create its own mental strain.

On the other hand, the abundance of news about the Covid-19 epidemic, the origins of which are sometimes unknown, makes employees more fearful of engaging in activities outside the house, even when the requirements of life and the family's economic strain necessitate such activities. Such circumstances will inevitably result in confrontation. When anxiety is mixed with conflict, mental stress is exacerbated. As can be seen from the description above, uncertainty about the situation, economic troubles, lower salary, or even layoffs are all factors that contribute to workplace stress.

\section{Stress in the Family}

WFH is adopted in the event of a Covid-19 pandemic, all family members meet at home daily and at any time. Thus, housewives bear the heaviest burden in carrying out their duties. Apart from performing ordinary household tasks, moms must accompany their children to homeschool, and it is not unusual for women to assume the position of instructor. The load that housewives face is not simply double birden, but may be rather substantial. One may argue that suddenly, all domestic issues are delegated to housewives. This is the probable source of family tension.

Children who are bored with online learning models and are unable to play and engage with their peers might feel family stress. Similarly, the husband, as the family's leader, who is required to work from home or is unemployed at home, has an effect on reducing productivity and income and can also contribute to family stress. Thus, family stress is a culmination of scholastic stress experienced by children and job stress experienced by parents (father or mother), all of which are compounded by less harmonious household circumstances, thereby enhancing the possibility for family stress. While stress is inescapable, it may be mitigated via constructive behavior. As a result, a complete and holistic approach to stress management is required. 


\section{Overcoming Worker Saturation in Facing Changes in the Work Environment}

Therefore, does the Covid-19 pandemic issue make us feel uneasy and fearful of job loss? Perhaps, and perhaps this will have an influence on our performance at work when we work from home. As a result, the following are practical advice for avoiding and reducing feelings of uncertainty at work when working from home:

\section{Improving Self Competence}

This work-from-home arrangement does not exempt us from strict work hours and stringent work processes. However, the moment has come for us to demonstrate to the organization that we are capable of doing well in the face of a pandemic. Our flexibility in managing work schedules enables us to enhance and build professional abilities that aid work and organizations in attaining goals, such as developing professional insight, language proficiency, information technology skills, or other talents. Additionally, we can develop interpersonal abilities, such as the ability to deal with change.

\section{Actively Participate}

The work-from-home situation necessitates that the work system we use on a daily basis at the office be reorganized and altered to accommodate the new circumstance. This must be accomplished in order for ourselves and the company to meet our job objectives. Proactively contributing ideas for action steps to address work difficulties enables us to gain indirect influence over the job we conduct in the company. We will be more acknowledged by the organization for our labor, and of course, we will contribute to the organization's performance throughout this period. Pandemic of Covid-19.

\section{Improve Communication}

Insecurity at work comes as a result of a lack of information about future events affecting the company. Effectively minimizing insecurity requires explicit, transparent, and early communication regarding organizational change (Landsbergis et al., 2014). Apart from being more candid about our working conditions, we as employees must also be more proactive in obtaining information and cooperating effectively with coworkers, managers, and colleagues in other departments on the organization's present conditions. It is thought that communication would strengthen our preparedness to deal with future challenges.

Enhancing your capacity to manage your emotions amid this epidemic. Everyone has a unique manner of coping with stress, and if used consistently, this strategy gradually develops into a habit. There are people that cope with stress in a healthy manner, while others exacerbate the situation by engaging in risky behavior. Effective stress management tactics include regular exercise, setting aside time for relaxation and self-care, balancing work and pleasure, and practicing time management and meditation. Consumption of alcohol and drugs, criminal behavior, procrastination of work, self-harm, and binge eating/drinking. Covid-19 is viewed by religious Indonesians as a litmus test that must be passed. One method to avoid stress is to have a positive attitude and spirituality. Making the most use of available time to engage in good activities while adhering to health regulations is one strategy for coping with stress during the Covid-19 epidemic.

\section{Conclusion}

The Covid-19 epidemic has elicited a variety of responses. To prevent the corona virus from spreading further, the government has implemented Work From Home (WFH) and Social Distancing measures. The pandemic's influence has compelled individuals to conduct all of their activities at home. The mood was extremely tense; the rush and bustle of daily life appeared to have died away, leaving no evidence of life. This disorder causes tension in certain 
individuals. The Covid-19 pandemic's stressors are grouped into three categories: academic stress, work stress, and family stress. Existing stress must be managed well in order to avoid becoming disturbed, but rather eustress. Some of the stress that occurs is a result of unreliable news or information, which can create worry and panic in the society. As a result, it is critical to choose and filter information carefully and thoroughly. Due to the introduction of WFH, the majority of activities, including teaching and learning, are now conducted online. These settings breed boredom, which results in academic stress. However, one might argue that the plus side is that it forces teachers/lecturers and students/students to be IT savvy and acclimated to accessing online media. This situation fosters the development of fruitful creative thoughts. The capacity to adapt to and appreciate current circumstances transforms stress from distress to eustress.

\section{References}

DiMatteo, M. R. (2004). Social support and patient adherence to medical treatment: a metaanalysis. Health psychology, 23(2), 207.

Gaines, J., \& Jermier, J. M. (1983). Emotional exhaustion in a high stress organization. Academy of Management journal, 26(4), 567-586.

Janis, I. L. (2016). Psychological stress: Psychoanalytic and behavioral studies of surgical patients. Academic Press.

Kakiashvili, T., Leszek, J., \& Rutkowski, K. (2013). The medical perspective on burnout. International journal of occupational medicine and environmental health, 26(3), 401-412.

Landsbergis, P. A., Grzywacz, J. G., \& LaMontagne, A. D. (2014). Work organization, job insecurity, and occupational health disparities. American journal of industrial medicine, 57(5), 495-515.

Maslach, C., \& Leiter, M. P. (2016). Burnout. In Stress: Concepts, cognition, emotion, and behavior (pp. 351-357). Academic Press.

McCoy, J. M., \& Evans, G. W. (2005). Physical work environment. Handbook of work stress, 219-245.

Paul, M., \& Saha, P. (2016). Spirituality as a potential psychological capital tool to deal with academic stress among management students. IUP Journal of Organizational Behavior, 15(4), 46.

Peterson, U., Demerouti, E., Bergström, G., Samuelsson, M., Åsberg, M., \& Nygren, Å. (2008). Burnout and physical and mental health among Swedish healthcare workers. Journal of advanced nursing, 62(1), 84-95.

Rubery, J., Ward, K., Grimshaw, D., \& Beynon, H. (2005). Working time, industrial relations and the employment relationship. Time \& Society, 14(1), 89-111 